
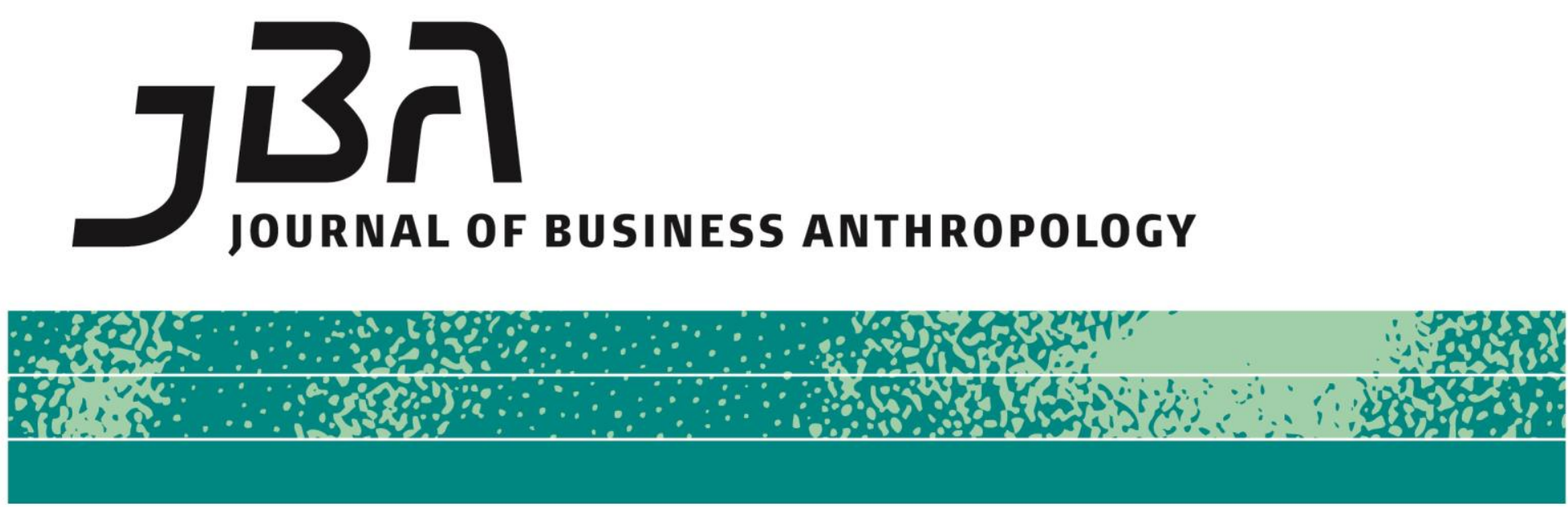

\title{
Working in Liminal States: Fluidity and Transformation in Organizations
}

Maryann McCabe and Elizabeth K. Briody

This special issue of the Journal of Business Anthropology grew out of a panel, "Liminality and Crossing Boundaries in Applied Anthropology," held at the 2013 American Anthropological Association Annual Meeting in Chicago, IL. The authors presented papers seeking to explore how business anthropologists continually operate in and across boundaries and work in liminal states and spaces. They called on the fruitful concept of liminality to make sense of their work because business anthropologists are enmeshed in complex material assemblages with diverse actors, products, and markets, discourses, and ideologies. The session led to a renewed consideration of liminality and of how embracing liminal space and time affords anthropologists opportunity to collaborate with others, act within multiple realities, and be change agents in organizations where they are working and/or consulting.

This issue pursues the "betwixt and between" idea of liminality (Turner 1967:93), a transitory stage associated with life stage rituals, and examines it from a perspective of enduring fluidity and movement. Whether applying their skills to consumer research or organizational culture, business anthropologists are constantly engaging with people in different disciplines, professions and functional areas of organizations. As members of teams conducting collaborative ethnography, business anthropologists are continually translating different worlds of meaning to
Page 1 of 12

JBA Special Issue 2: 1-12, Spring 2016

(C) The Author(s) 2016 ISSN 2245-4217

www.cbs.dk/jba 
reach consensus and bring their projects to fruition. The papers in this issue describe liminal experiences of anthropologists working with corporations and other organizations. They show how creative and productive an expanded notion of the liminal state has become in practicing business anthropology. Taken as a whole, the papers offer a view of liminality that is oriented to understanding the global economy, its increasingly diverse and mobile work force, and the recurring need for innovation in competitive marketplaces.

\section{Expanding the notion of liminality}

The idea of liminality has occupied a central place in anthropological thought since its earliest conception by Arnold van Gennep (1960) and key works by Victor Turner $(1957,1967,2007)$. For both of these scholars, liminality was a transitory stage through which the social person or community passes. From their perspective, liminality was confined in time and space, specifically in rituals, so that there was a beginning and an end to liminal time and space. Van Gennep defined three phases in life stage rituals such as birth and marriage: separation from society; a period of transition or liminality; and reincorporation into society. Passing through the liminal phase is a transformational experience, according to van Gennep, because the social person assumes new rights and obligations as a member of society. Turner, concerned with the social order, also considered the liminal phase transformational because rituals resolve and restore contradictory principles of social structure such as the paradox between matriliny and virilocality in Ndembu life. His analysis of the symbolism involved in Ndembu rituals provides deep understanding of the sensory experience in rituals and the semantic structure of contradictions in Ndembu society. Following van Gennep and Turner, the authors in this issue take up the idea of liminality as a transformational process, to explain the roles of the anthropologist working in the business world and, in some cases, the changes experienced by those collaborating with anthropologists.

In contrast to the idea of liminality as a transitory stage that one passes through and completes once and for all (for example, puberty), we can conceive of liminality as a fluid state, or situation, where one is constantly moving between different worlds. Anthropologists engage in collaborative ethnography and planned change, where projects with clients require translation of at least some aspects of the worldviews of other project participants. They are well suited to this task. Moving across boundaries and translating meaning from one context to another is an essential part of the anthropological endeavor. In business settings, anthropologists assume the role of trying to make different points of view mutually intelligible to people working on client projects. Liminality becomes a part of everyday work life as business anthropologists become involved in project after project. Even if some projects include the same 
people or people from the same disciplines, professions, and functional areas of an organization, translation is ongoing. The practices of project participants reflect different ontologies, which, in the Latourian sense, imply that the process of translation goes on forever because we cannot speak in the ontology of others, but only try to represent it (Latour 2013). Based on Latour's view of the translation of knowledge and practices, business anthropologists are always working in a fluid and never-ending state of liminality. Their experience differs from traditional fieldwork where anthropologists enter and leave a site after an extended stay. Doing collaborative ethnographic fieldwork is the everyday working experience of business anthropologists. The liminal state in which they work allows them to act as organizational change agents based on the research, analysis and teamwork they perform.

Liminal movement is central to business anthropology. Given the participatory nature of collaborative ethnography and its potential for change, the anthropologist is engaged in planning and negotiating the design and use of client projects with other team members, while also being involved in observing the latter's practices. This observation of other team members, what Luhmann (2012) calls "second-order observation," is purposeful. As Luhmann notes, it "entails active intervention in a situated manner" (2012:59). That is, the anthropologist takes on the role of team facilitator in the collaborative process. While coming to grips with his/her own perceptions of situations, the anthropologist is trying to understand and translate the perceptions of fellow team members (who may include other ethnographers, organizational members and/or consumers). Continual interaction creates a paradox in which the anthropologist is always detached, yet connected. That is, the anthropologist repeatedly detaches himself or herself from one reality in order to connect with another over the life of the project. The movement is continuous. Thus, liminality is a more active and lasting state in business anthropology than the transitional stage envisioned in earlier theoretical conceptions.

\section{Liminality in business anthropology}

One way to describe the work that anthropologists do in the business world is to say that they are involved in making something new related to the design, marketing and delivery of products and services, or to an assessment of the organizational culture and its potential for change. They conduct collaborative ethnography and engage in innovation and change to: (1) design products that will be useful to consumers, beneficial to society and sustainable in relation to the environment; (2) develop marketing and advertising communications to foster resonance between consumers and brands; and (3) help re-structure organizations to improve performance and/or create seamless customer experiences of the brand. So the work of business anthropologists entails everything 
from developing new goals, and the processes required to achieve them, to designing new products and services, to fashioning communications, and above all, creating consensus around them. Collaborative ethnography stems from organizations identifying opportunities in the marketplace and leads to providing solutions and improvements for a complex and shifting world. In this sense, the liminal state of business anthropologists is oriented to innovation and change. Companies, whether for profit or nonprofit, are ever-altering in response to customers and markets. As Trentmann (2009) suggests, routine and rupture are never far apart in the everyday life practices of consumers and organizations.

The authors in this issue point out that liminality is marked both by flux and ambiguity, as well as by degrees of flexibility and adaptability. A liminal state evokes innovation and creativity, although, as some of the articles demonstrate, innovation and change can generate liminality. A liminal state is characterized by a loosening of moorings, expected disruption, and openness to new ideas and behavior. When business anthropologists engage in collaborative ethnography and consulting, the implicit if not explicit purpose is to cause change: such as revising objectives and work practices, designing new products, or re-positioning brands. Interacting with others on the research team, business anthropologists play multiple roles: not only the traditional role of insight purveyor, but also the roles of knowledge broker and change agent (Beers 2016). As knowledge brokers, business anthropologists translate across professional and organizational boundaries to set up an environment for exchanges of ideas among team members and for imagining and immersing themselves in "what-if" scenarios. Beers (2016) notes that this does not happen spontaneously without formal or informal workshops and promptings-such as use of facilitation techniques that encourage team members to be open, exploratory and disruptive. The fluidity and movement of the liminal state sets the stage for business anthropologists to cross boundaries and act as change agents.

\section{The liminal state and transformation}

The liminal state has the potential to become transformative for organizations and individuals. Following Ingold (2013), we can think about transformation backwards and forwards. With a backward gaze, we see outcomes. For example, we can point to re-structured organizations, new brand communications, and fresh product designs. These outcomes reflect changes in organizations and the way those organizations relate to consumers, employees, and other stakeholders. From a forward look, we see emergent processes. Working on client projects is a transformative experience for anthropologists, as they grapple with issues facing clients and learn about business and consumer practices concerning products and brands, as well as broader economic, political and social contexts of 
production and consumption. Insights gained from collaborative ethnographic research open vistas on possible ways to maneuver in the context within which team members are enmeshed. Research oriented to business implications is related to the traditional role of the anthropologist as insight purveyor applying new knowledge to solve client problems.

Working on client projects is also transformative in terms of second-order observations and translating perspectives of other team members, which is part of the anthropologist's role as knowledge broker. The self-discovery that comes from grasping aspects of different worldviews affects all project participants. Some participants will be able to articulate integrated understandings to address client issues. As those team members collaborate, they will be in a position to shape, revise and bring projects to completion. In some circumstances, participants will not reach agreement on their goals or on the ways to achieve them. Under both scenarios, the anthropologist is involved as change agent in the organization. The anthropologist's skill in moving in liminal space is a key element - a necessary but not sufficient condition - in the transformation of individuals and organizations.

Taking a forward look at transformative processes in formation, authors in this issue talk about their experiences working in a liminal state. The transformations that occur are what Ingold (2013) calls a correspondence, or bringing things "into a relation with one another" (2013:70). Correspondence requires being "able to recognize subtle cues in one's environment and to respond to them with judgment and precision" (2013:109-110). Anthropologists are carving space in the business world to do just that: recognize consumer cues for products; respond to other team members; and spur joint action within organizations and in the marketplace. Liminality provides grease and glue for the work at hand. It supplies the grease by encouraging people to understand how other team members are defining projects, interpreting ethnographic data, and using research results-all in different ways. It also can furnish the glue for reaching consensus and bringing projects to fruition. The business anthropologist working in a fluid and enduring liminal state can exert a strong and positive influence on the course and outcome of the work, the future of the organization's decisions, and the organizational communications and learning that result.

At the same time, liminality has the potential to flow into a less productive, effective, or desirable end state, both for organizational stakeholders and for the anthropologist. The broader cultural context-whether internal or external-affects the ways in which all participants respond to transition and to its potential. Sometimes participants are too wedded to their worldviews and are unable or unwilling to change or innovate. It may be too threatening for them to examine their hidden assumptions and beliefs, or too painful to consider 
the impact of the potential change on their role and authority in the organization. They may believe that the timing is not "right": that is, that change or innovation is too disruptive at this point in time and that other priorities deserve the organization's attention. If any or all of these factors are in play, a skillful anthropologist may be unable to assist the organization successfully through a transition, or may be unable to apply his/her knowledge and perspective to help the organization thrive. Thus, managing liminality in context can be quite challenging and not always successful.

\section{Articles in this issue}

The anthropologist/ethnographer authors exhibit a range of roles in the articles in this special issue. Two are professors (Gluesing and Miller) who describe actual or potential situations associated with liminality that arose when they were working with students on their student research projects. Gluesing focuses her attention on global virtual teams in which anthropologists are involved. Anthropologists working with such complex entities can use liminality to unleash creative solutions by breaking free from organizational constraints, developing new skills and knowledge, and initiating and maintaining new connections. Through training and coaching, they may be able to suggest that organizational members gather and review field notes, step into another person's shoes, and otherwise understand a situation from alternative perspectives. Like all organizational participants, they can use the fluidity of global teams to take action and experiment with possible solutions. Anthropologists, Gluesing argues, are well equipped for working in liminal spaces like global virtual teams because their work entails continuous transitioning between divergent perspectives.

Miller's article discusses the liminality affecting the transitions in performance of multiple-disciplinary teams. She refers to the "liminal territory" characterized by confusion and conflict, as individuals on teams engage first in articulating their disciplinary perspective, then attempt to synthesize multiple disciplinary viewpoints into a coherent whole, and finally create a holistic, transcendent approach that captures the system dynamics. These attempts are "messy" and often fail. Like Gluesing, Miller suggests that anthropologists can serve as team "guides" because of their methodological training, rapport-building experience, and competence in translating different perspectives.

Wall and Englert work in industry as ethnographers on Xerox teams at the Palo Alto Research Center (PARC). They "move" and "translate" between "practitioners" (study participants/users), researchers or technology designers, and other stakeholders. They find that the movement and translation process is iterative, with multiple transitions involving customers and relevant internal organizational members. A key goal for Wall and Englert is to help the teams arrive at an 
integrated or "co-constructed" perspective-a closer alignment-on new designs, products, and services. They point out that team members may not realize that they are entering into a liminal space-say, when developers realize "practitioners" do not use the technology in the way it was intended. An opportunity then emerges for the team to discuss and reflect upon the evidence; typically, further design changes result, enabling the team to move out and beyond the liminal space.

Olsen describes the roles she played in a New York-based advertising agency during the 1970s, ranging from bullpen artist to executive. She focuses on three particular advertising campaigns that resulted in her direct involvement with liminality. She discovered that as the three ad campaigns progressed, her cognitive dissonance heightened. With each campaign, she describes her own experience with the phases of separation, transition, and incorporation. While Olsen generally found the work exciting and creative, her feminist sensibilities and anthropological coursework stood in sharp contrast to the campaign messaging and her agency's values. She used a variety of strategies to cope with the liminality-including participant observation in the field, keeping a log (field notes and reflections) of client-agency-customer interactions, and taking a long-haul view of her advertising career. Ultimately, she made the decision to earn her Ph.D. in anthropology, leaving the day-to-day practicalities of advertising behind.

Briody held a series of volunteer positions on the Board of Trustees of an assisted living and nursing care community. At the time, she had been working for years as an anthropologist in industry and had recently completed a pro bono cultural study of this community. Like Olsen and Wall and Englert, she encountered liminality while preparing for and serving in the Board President role. A small but powerful minority of Board members and the Executive Director resisted the initiation of a capital campaign to renovate the facility. Her term was marked by ambiguity, inaction, clique formation, and overt conflict. Briody differentiates among three types of liminality, examining them in relationship to Turner's concept of social drama. She developed the countering resistance model based on the lessons she learned. Chief among them were the cultivation and maintenance of key relationships to mitigate liminality.

\section{Outcomes of liminal processes}

Rites of passage in cultures studied by Turner (1967) and others (e.g., Middleton and Kershaw [1965]; Radcliffe-Brown [1922]) were integrated into community life and occurred repeatedly in a patterned way. Even though the rituals were new to the initiates, many members of the community had experienced them at some point in the past, and others possessed local knowledge about the processes involved and the expected end results. Indeed, these rituals linked directly to the community's 
shared beliefs, norms, and practices and served to reinforce them.

Liminal states and spaces in contemporary organizations are emergent processes and do not always follow a predictable pattern or have predictable outcomes. Liminality can be unexpected, taking individuals and organizations by surprise. Organizational leaders may not be able to cope with the confusion and ambiguity. Even anthropologists who are "of" a particular organization, and/or have experienced liminality in organizational settings, do not generally know $a$ priori the processes and outcomes associated with a liminal period or space. It is difficult to anticipate what is likely to happen, in what sequence, and with what end result. Timing, interactions, strategies, and a host of other factors can affect the outcome.

Liminality can be purposeful and intentional (Wall and Englert, Gluesing). It can be used to help make sense of a liminal state or time (Olsen, Gluesing, Miller). It can encourage people to become reflexive, identify their cultural assumptions, be open to alternative points of view, and face complexity (Wall and Englert, Miller, Gluesing). However, knowing that an individual, group, or organization is experiencing liminality does not necessarily imply that it can always be used to advantage. It can affect the quality of interactions and behaviors that occur (Briody, Olsen, Miller). Transitions can be ripe with conflict for individuals (Olsen) and groups (Briody, Miller). Organizational stakeholders can resist change and innovation and hold on to their worldview such that the length and pace of the transition, as well as organizational outcomes, are at risk (Briody, Olsen, Miller). When that happens, the innovation or change can result in a partial or complete failure (Briody).

To leverage liminality productively, other aspects of the context (such as cultural rules, beliefs, expectations, sanctions) are required to support the transition. The two professors (Miller and Gluesing) were able to provide advice and counsel to their students and to the global team members with whom they worked; students appreciated the value of their newly acquired skills in preparation for their professional careers. The in-house ethnographers at Xerox participated as full team members, ensuring that customer usage aligned with design intent (Wall and Englert); otherwise, a poorly designed technology would have cost, time, and reputation implications.

Olsen's article represents a mix of outcomes. By her account, the three ad campaigns were successful. They satisfied the client and added to the growing reputation of the ad agency. However, as a budding anthropologist, she found the thematic content of two of the campaigns distasteful. Moreover, she indicated that her boss dismissed the relevance and usefulness of her anthropological skills (Olsen). The openness to new possibilities was not realized. She found herself launched into a liminal morass, rising with each successive campaign. 
Moreover, agency culture did not tolerate a collegial exchange of ideas; only her boss' inspiration and approach mattered.

Briody's article describes an organization's path through an eighteen-month liminal period during which philanthropy was widely contested. Board members found themselves in one of two opposing cliques whose firmed-up positions could not be bridged. There was no organizational consensus to seek a common solution to keep the doors of the long-term-care community open. The minority clique led by powerful insiders was able to derail philanthropic efforts, without offering a promising alternative approach, and despite the pending and immutable renovation deadline imposed by state authorities. Communitas as "an intense comradeship or egalitarianism" (Turner 2007:95) or "a generalized social bond" (96) never formed across the Board-a condition that could have led to the creation of trust and collaboration, and ultimately to a shared vision of the future. Thus, the hoped-for transition or transformation was not realized.

\section{What's new?}

This examination of liminal spaces, times, and people working in contemporary organizations has expanded our understanding of transitions. By their very nature, transitions entail movement and flow. Both are core to organizational culture and change. Nothing stands still as creativity, innovation, resourcefulness, imagination, and initiative gear up and take hold. The "storehouse of possibilities" of which Turner wrote (1990:12) emerges. But what do those transitions that have been characterized by liminality look like? What are the key attributes of those transitions? How much commonality is evident in the "betwixt and between" state in its appearance, tempo, and activities? What factors contribute to the beginning and end of these transitions?

All of the articles suggest, and some (Wall and Englert, Briody, Olsen) stress, the iterative nature of the behaviors that occur within transitions. Their findings indicate that transitions are often composed of multiple repetitive processes-often a back-and forth, or even a twosteps-forward-one step-back, trajectory. Discussions and debates appear as routine and critical dimensions of work-based activity. Input is gathered, sorted, understood, and used in preparation for each "round" of interactions. A single, linear path to some end point does not represent liminality accurately.

A second attribute of transitions is the variation tied to the liminality experience. Those in transition do not experience it consistently or uniformly. Miller and Gluesing's students, for example, found it necessary to switch back and forth between roles of project researcher/consultant, team member, and student. Olsen indicates that her advertising experience was "punctuated by periods of liminality" and 
that her cognitive dissonance increased during the ad campaigns. For her part, Briody reports that the liminality tied to the Board of Trustees was interspersed with numerous interventions as members attempted to resolve opposing views and achieve consensus. She also points to the fluctuating pattern of Board resignations as an indication that members reacted differently to liminality-some with lower tolerances than others.

Liminality fluctuates during transitions. Wall and Englert report that their design teams experienced an ebb and flow in liminality as they shifted toward a closer alignment in perspectives. Briody's findings offer further insight into the fluidity of liminality. She identifies three distinct types, one of which (disrupting liminality) decreased over time, a second type (prophetic liminality) increased over time, and a third type (recurring liminality) emerged with cyclic regularity. Liminality is heterogeneous, then, in terms of transition time frames. Olsen's and Briody's articles report extended time frames in which liminality was in play, in contrast to the liminality experienced by Gluesing and Miller's students and Wall and Englert's design teams. Indeed, we hypothesize that the longer an individual, group, or organization remains mired in liminality, the less likely it is for that liminal space or place to result in a productive outcome.

A third feature entails anthropological preparation to help individuals and organizations under liminal conditions. Anthropologists have the training and are often positioned to help individuals and organizations during "betwixt and between" states and spaces. First, they typically have exposure to the concept-both through the literature and experiential learning. Their movement back and forth between their fieldwork, field notes, and literature (emic to etic) requires an understanding and appreciation of multiple perspectives (Gluesing). In addition, anthropologists can and do play important roles in facilitating understanding of and action in complex projects. They are able to dissect the multiplicity of viewpoints found on multiple-disciplinary, developercustomer, and/or global projects where ambiguity reigns and a shared approach has not yet been articulated (Miller, Wall and Englert, Gluesing).

Descriptions in three of the articles indicate anthropology's value in real time (Miller, Wall and Englert, Gluesing). Also of relevance and usefulness are liminal experiences explored retrospectively as historical narratives (Olsen, Briody). Olsen emphasizes the importance of anthropological techniques that helped her cope with liminality. Briody summarizes the lessons she learned about liminal circumstances-specifically, those related to agreement on strategy and collaboration. By applying the combination of method, theory, and practice to liminality-whether in current or past projects-anthropologists are positioned to help organizations of the present and future understand their culture and work effectively within it. 
Finally, the articles reveal the extent of the anthropologist's effect on organizational issues. That effect can range from ephemeral to longlasting when we consider the roles of business anthropologists (insight purveyor, knowledge broker, and change agent, as discussed above) within the framework of social life as mobility, flow and movement (Cresswell 2006; Lefebvre 2013). Across the five articles, the anthropologists were successful as insight purveyors, but varied in their impact as knowledge brokers and change agents. In three of the articles, the anthropologists moved the organizational change process forward by acting like a coach or teacher (Miller, Wall and Englert, Gluesing). They encouraged the development of mutual understanding and innovative solutions and reported instances of sustained high performance. In other words, the coaching or teaching proved effective, was adapted for use by organizational members, and had a long-term effect on organizational outcomes.

In the Olsen and Briody articles, their organizational effect was not durable. The change process became stymied because key people who needed to buy into the process refrained from doing so. Both organizations were tightly-controlled hierarchies with little room for deviation from what the key leader(s) wanted or what tradition deemed appropriate. Indeed, organizational innovation was not routinely tolerated. Persuasion and logic were insufficient in changing leadership perspectives. Under such circumstances, any knowledge broker or change agent would likely face similar disappointing outcomes.

We hope that you enjoy these articles!

\section{References}

Beers, R. 2016. Humanizing organizations: Researchers as knowledge brokers and change agents. In Collaborative ethnography in a business environment. M. McCabe, ed., Walnut Creek, CA: Left Coast Press, in press. Cresswell, T. 2006. On the move: Mobility in the modern western world. New York, NY: Routledge.

Ingold, T. 2013. Making: Anthropology, archeology, art and architecture. London, UK: Routledge.

Latour, B. 2013. An inquiry into modes of existence: An anthropology of the Moderns. C. Porter, trans. Cambridge, MA: Harvard University Press.

Lefebvre, H. 2013. Rhythmanalysis: Space, time and everyday life. London, UK: Bloomsbury.

Luhmann, N. 2012. Introduction to systems theory. Cambridge, UK: Polity.

Middleton, J. and G. Kershaw. 1965. The Kikuyu and Kamba of Kenya. London, UK: International African Institute. 
Radcliffe-Brown, A.R. 1922. The Andaman islanders: A study in social anthropology. Cambridge, UK: Cambridge University Press.

Trentmann, F. 2009. Disruption in normal: Blackouts, breakdowns and the elasticity of everyday life. In Time, consumption and everyday life: Practice, materiality and culture. E. Shove, F. Trentmann, and R. Wilk, eds. Oxford, UK: Berg, 67-84.

Turner, V.W. 1957. Schism and continuity in an African society: A study of Ndembu village life. Manchester, UK: University of Manchester Press.

Turner, V.W. 1967. The forest of symbols: Aspects of Ndembu ritual. Ithaca, NY: Cornell University Press.

Turner, V.W. 2007. The ritual process: Structure and anti-structure. New Brunswick, NJ: Aldine Transaction.

Turner, V. 1990. Are there universals of performance in myth, ritual, and drama? In By means of performance: Intercultural studies of theatre and ritual. R. Schechner and W. Appel, eds. Cambridge, UK: Cambridge University Press, 8-18.

van Gennep, A. 1960. The rites of passage. M. Vizedom and G. Caffee, trans. Chicago, IL: University of Chicago Press.

Maryann McCabe, Ph.D., is founder and principal of Cultural Connections LLC, a consumer research consultancy. She works for Fortune 500 companies and advertising agencies in the U.S., Europe and Japan. Her specialization is branding, positioning and marketing strategy in the automotive, banking, beauty, food, health care, pharmaceutical and technology industries. She is also senior lecturer at the University of Rochester, Department of Anthropology, where she teaches courses on market research, entrepreneurship and sustainability, and works with students who earn an entrepreneurial study year. Her ethnographic research has been published in academic books and journals including Consumption Markets \& Culture, Journal of Consumer Culture, Human Organization, and Journal of Business Anthropology. She is currently Chair of the Public Policy Committee, Society for Applied Anthropology. She may be reached at $\underline{\text { mm@cultureconnex.com. }}$

Elizabeth K. Briody, Ph.D., is a cultural anthropologist who has been engaged in organizational-culture change for over 25 years. She is founder and principal of Cultural Keys LLC, a consultancy that helps organizations transform their culture, reach their potential, and attract and retain new customers. She has worked in health care, manufacturing, consumer products, service industries, research institutions, and other industries in the U.S. and abroad. Her most recent books include Transforming Culture: Creating and Sustaining Effective Organizations (co-authored with Robert T. Trotter, II and Tracy L. Meerwarth, Palgrave, 2014) and The Cultural Dimension of Global Business (co-authored with Gary Ferraro, 7th ed., Pearson, 2013). Elizabeth is currently a Board member of the American Anthropological Association. She may be reached at elizabeth@culturalkeys.us. 